\title{
Effects of soil and climatic conditions on the variation in some ryegrass seed crops
}

\author{
M.D. CRAIGHEAD ${ }^{1}$ and I.J. YULE ${ }^{2}$ \\ ${ }^{1}$ Nutrient Solutions Ltd, R.D. 2, Rangiora \\ ${ }^{2}$ New Zealand Centre for Precision Agriculture, Massey University, Palmerston North
}

\begin{abstract}
Site specific data for ryegrass seed crops has been obtained from two precision agriculture projects in Canterbury. Using yield maps and proximal sensors, the temporal and spatial variability within and between crops was quantified. In general, the best ryegrass seed yields were on the medium textured soils within a paddock. The lightest textured parts of a paddock could yield as well or better than these areas, particularly in seasons with cool springs, and in average to dry seasons provided irrigation was optimal. In contrast, heavier textured soils only yielded as well as medium textured soils if they were not overly wet (or cool) early in the season and in very dry years, when irrigation could not meet crop water demands, or in dryland situations.

When irrigation was altered on perennial ryegrass by restricting moisture in November, there was greater reduction in seed yield in the lighter textured areas compared to the medium textured areas of a paddock.
\end{abstract}

Extra nitrogen applied in late October improved yields in the medium textured part of the paddock but had a slight negative effect in the lighter areas of the paddock. In a trial using the plant growth regulator, Moddus, application was only beneficial in the medium textured parts of the paddock.

Interpretation of ryegrass seed yield maps can be confounded by crop management decisions such as grazing, irrigation and harvest conditions. Late harvesting decreased seed yield so that the effects of soil texture and moisture were less evident. Farmers without this technology can use soil maps, aerial photographs and observation to identify areas of potential difference within a paddock. Targeting soil sampling, plant dry matter, soil moisture and perhaps nutrient analysis to major areas of difference can be useful in developing a zonal management system.

Keywords: crop management, precision agriculture, ryegrass seed crops, seed yield maps 
